\title{
Regulation of endogenous glucose production after a mixed meal in type 2 diabetes
}

Parag Singhal, Andrea Caumo, Peter E. Carey, Claudio Cobelli and Roy Taylor Am J Physiol Endocrinol Metab 283:E275-E283, 2002. First published 2 April 2002;

doi:10.1152/ajpendo.00424.2001

You might find this additional info useful...

This article cites 66 articles, 32 of which can be accessed free at:

http://ajpendo.physiology.org/content/283/2/E275.full.html\#ref-list-1

This article has been cited by 15 other HighWire hosted articles, the first 5 are:

Long-Term Inhibition of the Glucagon Receptor with a Monoclonal Antibody in Mice Causes Sustained Improvement in Glycemic Control, with Reversible $\alpha$-Cell Hyperplasia and Hyperglucagonemia

Wei Gu, Hai Yan, Katherine A. Winters, Renée Komorowski, Steven Vonderfecht, Larissa Atangan, Glenn Sivits, David Hill, Jie Yang, Vivian Bi, Yuqing Shen, Sylvia Hu, Tom Boone, Richard A. Lindberg and Murielle M. Véniant

J Pharmacol Exp Ther, December , 2009; 331 (3): 871-881.

[Abstract] [Full Text] [PDF]

Effects of Type 2 Diabetes on Insulin Secretion, Insulin Action, Glucose Effectiveness, and Postprandial Glucose Metabolism Ananda Basu, Chiara Dalla Man, Rita Basu, Gianna Toffolo, Claudio Cobelli and Robert A. Rizza

Dia Care, May , 2009; 32 (5): 866-872.

[Abstract] [Full Text] [PDF]

Fully Human Monoclonal Antibodies Antagonizing the Glucagon Receptor Improve Glucose Homeostasis in Mice and Monkeys

Hai Yan, Wei Gu, Jie Yang, Vivian Bi, Yuqing Shen, Eunkyung Lee, Katherine A. Winters, Renée Komorowski, Cheng Zhang, Jennifer J. Patel, Dorothy Caughey, Gary S. Elliott, Yvonne Y. Lau, Jin Wang, Yue-Sheng Li, Tom Boone, Richard A. Lindberg, Sylvia Hu and Murielle M. Véniant

J Pharmacol Exp Ther, April , 2009; 329 (1): 102-111.

[Abstract] [Full Text] [PDF]

Insulin Administration and Rate of Glucose Appearance in People With Type 1 Diabetes Mary E. Pennant, Leslie J.C. Bluck, M. Loredana Marcovecchio, Burak Salgin, Roman Hovorka and David B. Dunger

Dia Care 2008; 31 (11): 2183-2187.

[Abstract] [Full Text] [PDF]

Increased glucose production in mice overexpressing human fructose-1,6-bisphosphatase in the liver

Sherley Visinoni, Barbara C. Fam, Amy Blair, Christian Rantzau, Benjamin J. Lamont, Russell Bouwman, Matthew J. Watt, Joseph Proietto, Jenny M. Favaloro and Sofianos Andrikopoulos Am J Physiol Endocrinol Metab, November 1, 2008; 295 (5): E1132-E1141. [Abstract] [Full Text] [PDF]

Updated information and services including high resolution figures, can be found at: http://ajpendo.physiology.org/content/283/2/E275.full.html

Additional material and information about AJP - Endocrinology and Metabolism can be found at: http://www.the-aps.org/publications/ajpendo

This infomation is current as of October 7, 2011.

AJP - Endocrinology and Metabolism publishes results of original studies about endocrine and metabolic systems on any level of organization. It is published 12 times a year (monthly) by the American Physiological Society, 9650 Rockville Pike, Bethesda MD 20814-3991. Copyright (C) 2002 by the American Physiological Society. ISSN: 0193-1849, ESSN: 1522-1555. Visit our website at http://www.the-aps.org/. 


\title{
Regulation of endogenous glucose production after a mixed meal in type 2 diabetes
}

\author{
PARAG SINGHAL, ${ }^{1}$ ANDREA CAUMO,${ }^{2}$ PETER E. CAREY,${ }^{1}$ \\ CLAUDIO COBELLI, ${ }^{2}$ AND ROY TAYLOR ${ }^{1}$ \\ ${ }^{1}$ Diabetes Research Group, School of Clinical Medical Sciences, University of \\ Newcastle upon Tyne, Newcastle upon Tyne NE2 4HH, United Kingdom; and \\ ${ }^{2}$ Dept of Electronics and Informatics, University of Padova, Padua I35131, Italy \\ Received 25 September 2001; accepted in final form 24 March 2002
}

\begin{abstract}
Singhal, Parag, Andrea Caumo, Peter E. Carey, Claudio Cobelli, and Roy Taylor. Regulation of endogenous glucose production after a mixed meal in type 2 diabetes. Am J Physiol Endocrinol Metab 283: E275-E283, 2002. First published April 2, 2002; 10.1152/ajpendo.00424.2001. The extent and time course of suppression of endogenous glucose production (EGP) in type 2 diabetes after a mixed meal have been determined using a new tracer methodology. Groups of age-, sex-, and weight-matched normal controls $(n=8)$ and diet-controlled type 2 diabetic subjects $(n=8)$ were studied after ingesting a standard mixed meal (550 kcal; $67 \%$ carbohydrate, $19 \%$ fat, $14 \%$ protein). There was an early insulin increment in both groups such that, by $20 \mathrm{~min}$, plasma insulin levels were $266 \pm 54$ and $190 \pm 53 \mathrm{pmol} / \mathrm{l}$, respectively. EGP was similar basally $\left[2.55 \pm 0.12 \mathrm{mg} \cdot \mathrm{kg}^{-1}\right.$. $\mathrm{min}^{-1}$ in control subjects vs. $2.92 \pm 0.16 \mathrm{mg} \cdot \mathrm{kg}^{-1} \cdot \mathrm{min}^{-1}$ in the patients $(P=0.09)]$. After glucose ingestion, EGP declined rapidly in both groups to $\sim 50 \%$ of basal within $30 \mathrm{~min}$ of the meal. Despite the initial rapid decrease, the EGP was significantly greater in the diabetic group at $60 \min (1.75 \pm$ 0.12 vs. $\left.1.05 \pm 0.14 \mathrm{mg} \cdot \mathrm{kg}^{-1} \cdot \mathrm{min}^{-1} ; P<0.01\right)$ and did not reach nadir until $210 \mathrm{~min}\left(0.96 \pm 0.17 \mathrm{mg} \cdot \mathrm{kg}^{-1} \cdot \mathrm{min}^{-1}\right)$. Between 60 and 240 min, EGP was $47 \%$ higher in the diabetic group $\left(0.89 \pm 0.09\right.$ vs. $1.31 \pm 0.13 \mathrm{mg} \cdot \mathrm{kg}^{-1} \cdot \mathrm{min}^{-1}, P<$ 0.02 ). These data quantitate the initial rapid suppression of EGP after a mixed meal in type 2 diabetes and the contribution of continuing excess glucose production to subsequent hyperglycemia.

liver; insulin sensitivity
\end{abstract}

THE LIVER PLAYS A PRIMARY ROLE in maintaining the fasting plasma glucose concentration within a very narrow range in normal subjects, the basal rate of tissue glucose uptake being precisely equaled by the rate of endogenous glucose production (EGP). After the ingestion of a meal, this delicate balance is disrupted, and maintenance of normal glucose homeostasis in the fed state depends on suppression of EGP, augmentation of glucose uptake by splanchnic tissues and muscle, and stimulation of glucose oxidation (19). Because meals tend to be taken every few hours during the day, knowledge about these processes is central to the ap-

Address for reprint requests and other correspondence: R. Taylor, School of Clinical Medical Sciences, The Medical School, Framlington Place, Newcastle upon Tyne NE2 4HH, UK (E-mail: roy.taylor @ncl.ac.uk). preciation of both normal energy metabolism and the pathophysiology of non-insulin-dependent diabetes, a condition characterized by marked postprandial hyperglycemia $(10,21,30)$. Hepatic insulin resistance causing faulty control of glucose production is believed to exacerbate the hyperglycemia $(20,27)$. The practical importance of this has been emphasized by data linking the extent of postprandial hyperglycemia with the vascular complications of diabetes $(18,28)$.

Information on insulin regulation of glucose control in the fed state has previously been inferred from studies using intravenous glucose under the nonphysiological condition of constant hyperinsulinemia. Many studies have followed the fate of a pure glucose load $(24,33,37,38)$, but the metabolic response to a glucose load differs from that after a mixed meal $(23,35,44)$. Furthermore, the studies of endogenous glucose release after oral glucose have utilized a constant infusion of a glucose tracer, such as that used during steady-state glucose infusion experiments to achieve constant specific activity of plasma glucose. However, the key variable in the assessment of endogenous glucose release is the tracer specific activity, referred not to plasma glucose concentration but to endogenous glucose concentration, i.e., that fraction of the plasma glucose originating from endogenous sources. Because the endogenous glucose concentration falls after eating, specific activity varies markedly during a constant glucose tracer infusion protocol, leading to non-steadystate errors in the calculation of EGP $(15,25,34,49)$. To minimize non-steady-state errors, it is necessary to reduce the changes in endogenous glucose specific activity by use of a variable tracer infusion protocol. Ideally, the tracer infusion is varied in such a way that endogenous specific activity remains constant during the meal absorption, and under these conditions the calculation of EGP becomes model independent.

This alternative approach of varying the tracer infusion rate was used as early as 1973 in experimental work in dogs (22) but only recently in humans (65). The technique has not previously been applied to type 2

The costs of publication of this article were defrayed in part by the payment of page charges. The article must therefore be hereby marked "advertisement" in accordance with 18 U.S.C. Section 1734 solely to indicate this fact. 
diabetes. By allowing direct measurement of both EGP and plasma insulin after eating, the hypothesis that insulin resistance operates at the level of the liver could be tested. The absolute contribution of hepatic dysregulation to postprandial hyperglycemia could also be defined. This paper describes the pathophysiological changes in EGP after a mixed meal by applying the new technique to matched groups of normal and type 2 diabetic subjects.

\section{MATERIALS AND METHODS}

Subjects. Type 2 diabetic subjects controlled for diet alone $(n=8)$ and age-, sex-, and weight-matched healthy volunteers $(n=8)$ were recruited. Athletes in training were excluded, as were any subjects with metabolic disease or controls with first-degree family history of type 2 diabetes. No subject was taking medication that might affect carbohydrate metabolism. The mean duration of diabetes was $3.9 \mathrm{yr}$. The clinical and metabolic characteristics of the subjects are shown in Table 1. For 3 days before study, subjects consumed their normal weight-maintaining diet and completed a dietary diary. The diabetic and control groups reported similar calorie intakes $(1,811 \pm 403$ vs. $1,976 \pm 581 \mathrm{kcal})$ and similar food composition (carbohydrate $239 \pm 46$ vs. $252 \pm 77 \mathrm{~g}$, fat $63 \pm 15$ vs. $78 \pm 23 \mathrm{~g}$, and protein $79 \pm 16$ vs. $83 \pm 23 \mathrm{~g}$ ). The nature, purpose, and potential risks of the study were explained to all the subjects, and their informed, voluntary, written consent was obtained before their participation. The study protocol was reviewed and approved by the Joint Ethics Committee, University of Newcastle upon Tyne.

Experimental protocol. Subjects were studied in the recumbent position after a 12 -h overnight fast. At $7 \mathrm{AM}$, an intravenous cannula for infusion was placed in an antecubital fossa vein, and a second cannula was placed in a distal forearm vein in a retrograde fashion, this hand being placed in a heated box at $50^{\circ} \mathrm{C}$ to allow sampling of arterialized blood. At time $-180 \mathrm{~min}$ a primed continuous $(0.40 \mu \mathrm{Ci} / \mathrm{min})$ infusion of $\left[3{ }^{-3} \mathrm{H}\right]$ glucose was started. The prime was $40 \mu \mathrm{Ci}$ in the control group but was adjusted according to fasting plasma glucose in the diabetic group to avoid delay in achieving steady-state plasma glucose specific activity (48). The prime in $10 \mathrm{ml}$ of normal saline was flushed through the cannula with $5 \mathrm{ml}$ of saline. A period of $180 \mathrm{~min}$ was allowed for equilibrium of tritiated glucose; the end of this equilibrium period was taken to be time zero. A liquid meal ( 550 kcal; $67.3 \%$ carbohydrate, $18.5 \%$ fat, $14.2 \%$ protein) including $2 \mathrm{~g}$ of $\left[2-{ }^{2} \mathrm{H}\right]$ glucose was consumed within $10 \mathrm{~min}$, starting at time zero. After the meal, the rate of infusion of tritiated glucose was adjusted to reproduce the anticipated pattern of endogenous glucose release after the meal. Subjects voided just before ingestion of the glucose load, and urine was collected at $210 \mathrm{~min}$ (diabetic group only) and at the end of the experiment for determination of urinary glucose loss. Glucose oxidation rates were calculated from indirect calo-

Table 1. Clinical characteristics of the study subjects

\begin{tabular}{lcc}
\hline \multicolumn{1}{c}{ Characteristic } & Normal Subjects & Diabetic Subjects \\
\hline Age, yr & $50.8 \pm 2.9$ & $52.4 \pm 2.9$ \\
Sex, M/F & $5 / 3$ & $5 / 3$ \\
Body mass index & $29.6 \pm 1.3$ & $30.1 \pm 1.2$ \\
Fasting glucose, mmol/l & $5.0 \pm 0.1$ & $7.7 \pm 0.5$ \\
Hb A $\mathrm{A}_{1 \mathrm{C}}, \%$ & $5.5 \pm 0.1$ & $7.2 \pm 0.4$ \\
\hline
\end{tabular}

Values are means $\pm \mathrm{SE}$. rimetry data derived by use of a constant-flow hood calorimeter (Delta Trac 17). Measurements were made over 20-min periods in the fasting state and at regular intervals after the meal. Fuel oxidation data were calculated using equations of Lusk (41). Frequent blood samples were taken for the determination of plasma glucose, $\left[2-{ }^{2} \mathrm{H}\right]$ glucose, $\left[3-{ }^{3} \mathrm{H}\right]$ glucose, lactate, free fatty acids, insulin, and glucagon.

Variable tracer infusion rate. The $\left[3{ }^{3} \mathrm{H}\right]$ glucose infusion rate was varied in a stepwise fashion to anticipate the decrease and subsequent increase in EGP after the meal. The protocol was determined iteratively in preliminary studies. The variable infusion protocol remained the same for both groups to avoid potential complicating factors, as the main aim of the study was to compare the pattern of postprandial EGP between the control and diabetic groups and was as follows: basal period, $100 \%$ of basal infusion rate; $0-5 \mathrm{~min}$, 100\%; 5-10 min, 90\%; 10-15 min, 75\%; 15-20 min, 55\%; 20-25 min, 40\%; 25-30 min, 30\%; 30-220 min, 20\%; 220$240 \mathrm{~min}, 30 \%$; $240-260 \mathrm{~min}, 35 \%$; $260-280 \mathrm{~min}, 40 \%$; $280-$ $300 \mathrm{~min}, 45 \%$; 300-400 min, 55\%; and 400-480 min, $65 \%$.

Calculations of EGP. The profile of exogenous glucose concentration, i.e., the component of total glucose concentration due to exogenous glucose ingestion, was initially calculated. Because this is proportional to the concentration of $\left[2-{ }^{2} \mathrm{H}\right]$ glucose, its calculation is straightforward and model independent (16). We then calculated the time course of endogenous glucose concentration, i.e., the component of total glucose concentration due to EGP only, by subtracting the calculated exogenous component from the measured total glucose concentration. The steady-state values of plasma clearance rate (PCR) and basal EGP (basal EGP $=$ PCR $\times$ basal glucose concentration) were estimated from the $\left[3-{ }^{3} \mathrm{H}\right]$ glucose decay curve after the primed continuous infusion of $\left[3{ }^{3} \mathrm{H}\right]$ glucose given $3 \mathrm{~h}$ before the administration of the meal (14). Subsequently, the time course of EGP was calculated from endogenous glucose concentration and $\left[3-{ }^{3} \mathrm{H}\right]$ glucose data. Because $\left[3-{ }^{3} \mathrm{H}\right]$ glucose had been infused to mimic the expected behavior of EGP, the specific activity given by the ratio of $\left[3-{ }^{3} \mathrm{H}\right]$ glucose to endogenous glucose was steady, thus allowing a more reliable estimation of EGP. EGP was calculated using the two-compartment model of Radziuk et al. (54). The concentration of $\left[3{ }^{-3} \mathrm{H}\right]$ glucose and the ratio between $\left[3-{ }^{3} \mathrm{H}\right]$ glucose and endogenous glucose concentration were smoothed using an algorithm based on stochastic nonparametric deconvolution (63).

Insulin sensitivity. The homeostatic model assessment (HOMA) index of insulin sensitivity was calculated using fasting insulin and glucose concentrations (43).

Analytical procedures. Plasma glucose concentration was measured by the glucose oxidase method on a Beckman glucose analyzer. Plasma insulin concentration was measured using an enzyme-linked immunosorbant assay kit (Dako) and plasma glucagon by radioimmunoassay (50). Plasma lactate was measured on perchloric acid extracts on a Cobas Bio centrifugal analyzer (Roche, Welwyn Garden City, UK) (29). Plasma FFA were measured by centrifugal enzymatic analysis (39). Atom percent enrichment of plasma $\left[2-{ }^{2} \mathrm{H}\right]$ glucose was determined by gas chromatography-mass spectrometry (8). Plasma $\left[3-{ }^{3} \mathrm{H}\right]$ glucose radioactivity was determined after deproteinization of plasma with $\mathrm{ZnSO}_{4}$ and $\mathrm{Ba}(\mathrm{OH})_{2}$, as described (56).

Statistical methods. Data are stated as means \pm SE. Student's two-tailed $t$-test and Pearson's correlation were employed as appropriate with the use of the Minitab statistical program (Minitab, State College, PA). 


\section{RESULTS}

Plasma glucose. After glucose ingestion, plasma glucose in the control group increased from a basal level of $4.8 \pm 0.1 \mathrm{mmol} / \mathrm{l}$ to peak concentration of $7.8 \pm 0.4$ $\mathrm{mmol} / \mathrm{l}$ at $60 \mathrm{~min}$ and returned to basal values between 180 and $240 \mathrm{~min}$ (Fig. 1). In the diabetic subjects, plasma glucose increased from a basal level of $6.8 \pm 1.2$ $\mathrm{mmol} / \mathrm{l}$ to a peak concentration of $14.2 \pm 2.2 \mathrm{mmol} / \mathrm{l}$ at $150 \mathrm{~min}$ (both $P<0.001$ compared with controls) and did not return to basal levels until $330 \mathrm{~min}$. The mean plasma glucose concentration in the diabetic subjects during the 8-h experimental period was $9.5 \mathrm{mmol} / \mathrm{l}$ compared with $5.7 \mathrm{mmol} / \mathrm{l}$ in the control group $(P<$ $0.001)$. The rise in enrichment of $\left[2-{ }^{2} \mathrm{H}\right]$ glucose in plasma was very similar in the two groups, diverging modestly only after 80 min (Fig. 2).

Plasma metabolites and hormones. There was no significant difference in the fasting insulin concentration in the two groups $(50 \pm 10 \mathrm{pmol} / \mathrm{l}$ in controls vs. $67 \pm 12 \mathrm{pmol} / \mathrm{l}$ in patients, $P=0.23$ ). After glucose ingestion, there was an early, brisk increment in both groups such that, by $20 \mathrm{~min}$, plasma insulin levels were $266 \pm 54$ and $190 \pm 53 \mathrm{pmol} / \mathrm{l}$ in the control and diabetic groups, respectively. Plasma insulin increased to a peak concentration at $60 \mathrm{~min}$ in the control group $(614 \pm 179 \mathrm{pmol} / \mathrm{l})$ and more slowly to peak concentration at $150 \mathrm{~min}$ in the diabetic group (449 $\pm 123 \mathrm{pmol} / \mathrm{l}$; Fig. 1). In the control group, plasma insulin levels returned to basal values between 240 and $270 \mathrm{~min}$, but in the diabetic group basal levels were not reached until $400 \mathrm{~min}$ after the meal. Immediately before the meal, plasma glucagon concentrations were similar in the two groups $(53.3 \pm 6.0 \mathrm{ng} / \mathrm{l}$ in control vs. $59.7 \pm$ $10.4 \mathrm{ng} / \mathrm{l}$ in patients, $P=0.3$ ). After glucose ingestion, plasma glucagon rose briskly in both groups to peak at $20 \mathrm{~min}(69.6 \pm$ vs. $94.2 \pm 15.1 \mathrm{ng} / \mathrm{l}$, respectively, $P=$ 0.17 ; Fig. 1). Plasma glucagon decreased in the control group to $36.6 \pm 2.3 \mathrm{ng} / \mathrm{l}$ at $150 \mathrm{~min}$ and returned to basal values between 300 and $360 \mathrm{~min}$. In the diabetic subjects, the plasma glucagon at $150 \mathrm{~min}$ was still elevated at $74.0 \pm 12.9 \mathrm{ng} / \mathrm{l}(P=0.03)$ and did not reach lowest concentrations until $270 \mathrm{~min}$. Plasma lactate levels were similar in control and diabetic subjects both fasting $(0.66 \pm 0.14$ vs. $0.58 \pm 0.07 \mathrm{mM})$ and

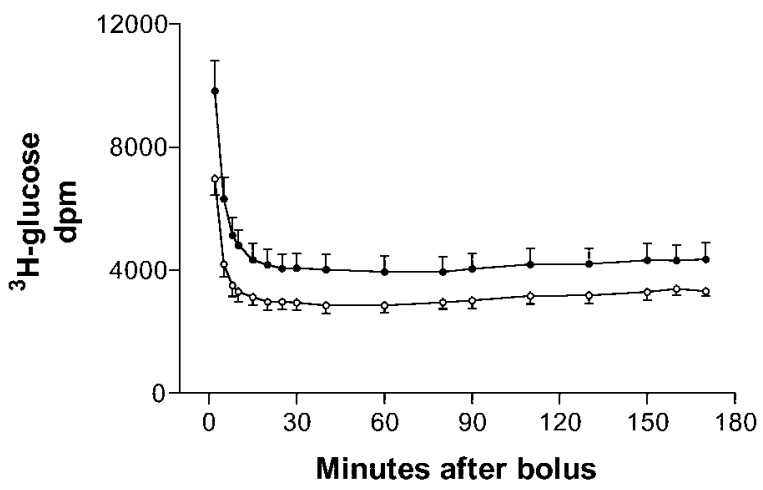

Fig. 1. Plasma specific activity during the primed continuous infusion of $\left[{ }^{3} \mathrm{H}\right]$ glucose during the basal period before the test meal.
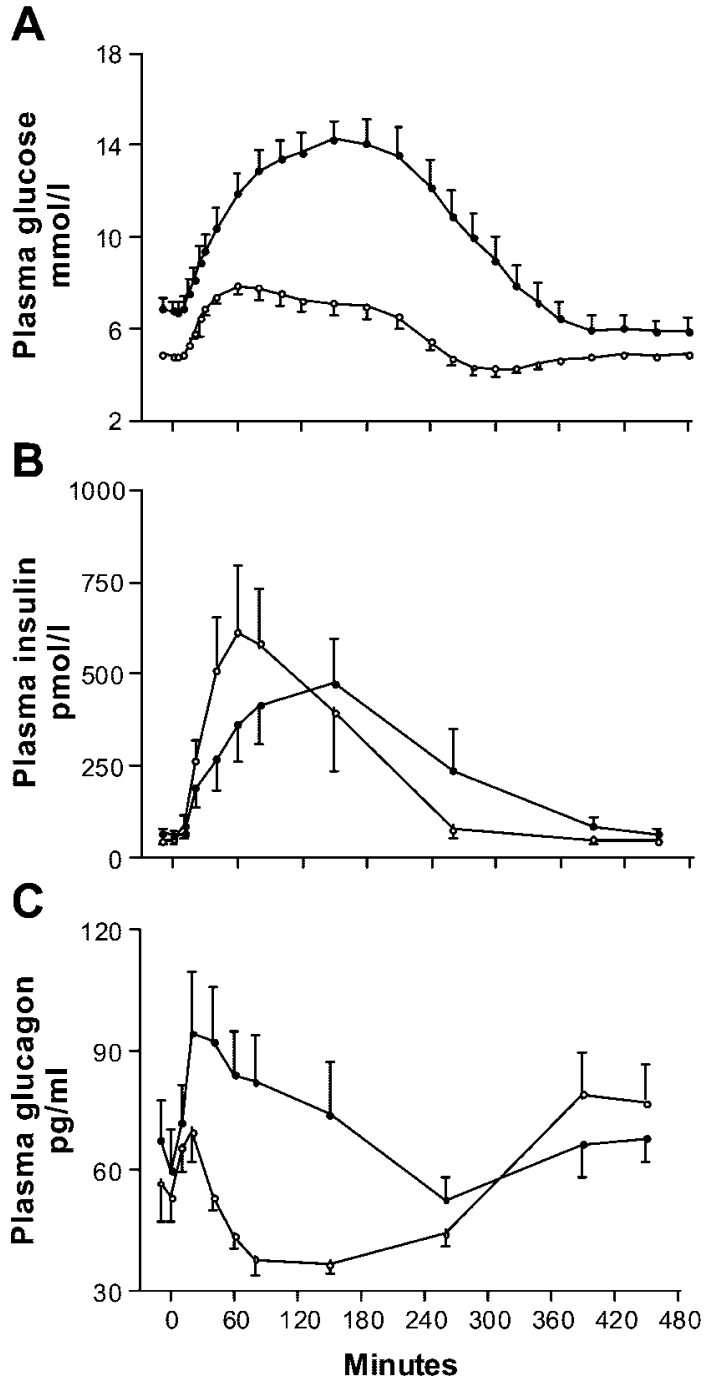

Fig. 2. Change in plasma glucose $(A)$, insulin $(B)$, and glucagon concentrations $(C)$ after the test meal in the type 2 diabetic group $(\bullet)$ and the matched normal control group (O). Data are shown as means $\pm \mathrm{SE}$

at peak ( $80 \mathrm{~min}: 0.95 \pm 0.11$ vs. $1.02 \pm 0.14 \mathrm{mM}$ ). The subsequent fall in plasma lactate was slightly but not significantly delayed in the diabetic subjects (150 min: $0.65 \pm 0.04$ vs. $0.99 \pm 0.18 \mathrm{mM}$, respectively).

Endogenous glucose output. Steady-state plasma levels of $\left[3-{ }^{3} \mathrm{H}\right]$ glucose were achieved in the basal period (Fig. 3).

Fasting EGP was $2.55 \pm 0.12 \mathrm{mg} \cdot \mathrm{kg}^{-1} \cdot \mathrm{min}^{-1}$ in control subjects vs. $2.92 \pm 0.16 \mathrm{mg} \cdot \mathrm{kg}^{-1} \cdot \mathrm{min}^{-1}$ in the patients $(P=0.09)$. After glucose ingestion, EGP declined rapidly in both groups to $\sim 50 \%$ of basal within 30 min of the meal (Fig. 4). The parallel rates of decline in EGP over this 30-min period are striking. In control subjects EGP decreased further and remained less than $1 \mathrm{mg} \cdot \mathrm{kg}^{-1} \cdot \mathrm{min}^{-1}$ until $240 \mathrm{~min}$ but recovered steeply thereafter. The greatest suppression was observed at $120 \mathrm{~min}\left(0.75 \pm 0.16 \mathrm{mg} \cdot \mathrm{kg}^{-1} \cdot \mathrm{min}^{-1}\right)$. Despite the initial rapid decrease in EGP in the diabetic group, the EGP was significantly greater than in con- 

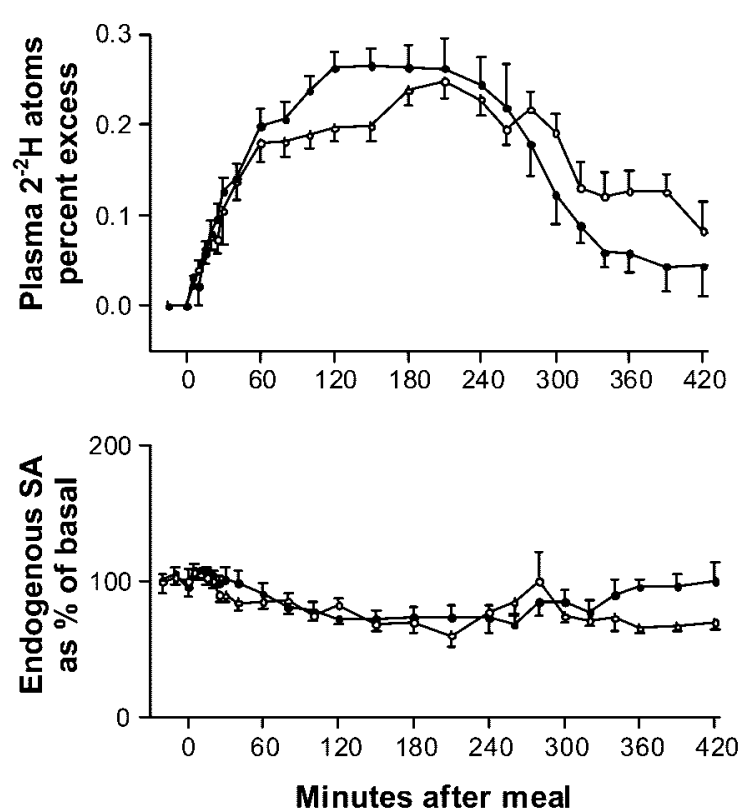

Fig. 3. Top: rate of absorption of meal glucose shown as atom percent excess of 2-D-glucose in plasma in the type 2 diabetic group (•) and the matched normal control group (O). Bottom: specific activity (SA) of endogenously derived glucose in plasma expressed as percentage of basal plasma glucose specific activity.

trols at $60 \min (1.75 \pm 0.12$ vs. $1.05 \pm 0.14$ $\left.\mathrm{mg} \cdot \mathrm{kg}^{-1} \cdot \mathrm{min}^{-1}, P<0.01\right)$ and did not reach nadir until $210 \mathrm{~min}\left(0.96 \pm 0.17 \mathrm{mg} \cdot \mathrm{kg}^{-1} \cdot \mathrm{min}^{-1}\right)$. Between 60 and 240 min, EGP was $47 \%$ higher in the diabetic group $\left(0.89 \pm 0.09\right.$ vs. $1.31 \pm 0.13 \mathrm{mg} \cdot \mathrm{kg}^{-1} \cdot \mathrm{min}^{-1}, P<$ 0.02 ). EGP recovered rapidly in nondiabetic subjects between 240 and $360 \mathrm{~min}$, plateauing thereafter. In the diabetic subjects the rise was less rapid ( 0.006 vs. 0.011 $\mathrm{mg} \cdot \mathrm{kg}^{-1} \cdot \mathrm{min}^{-1}$; Fig. 5).

At 60 min after the meal, the degree of suppression of EGP correlated both with plasma insulin $(r=-0.60$, $P<0.02)$ and with the insulin/glucagon ratio $(r=$ $-0.63, P<0.01$; Fig. 6 ). There was an inverse correlation between the HOMA index of insulin sensitivity and EGP 60 min after the meal in both the control $(r=$ $0.81, P<0.02)$ and diabetic groups $(r=0.82, P<0.02)$.

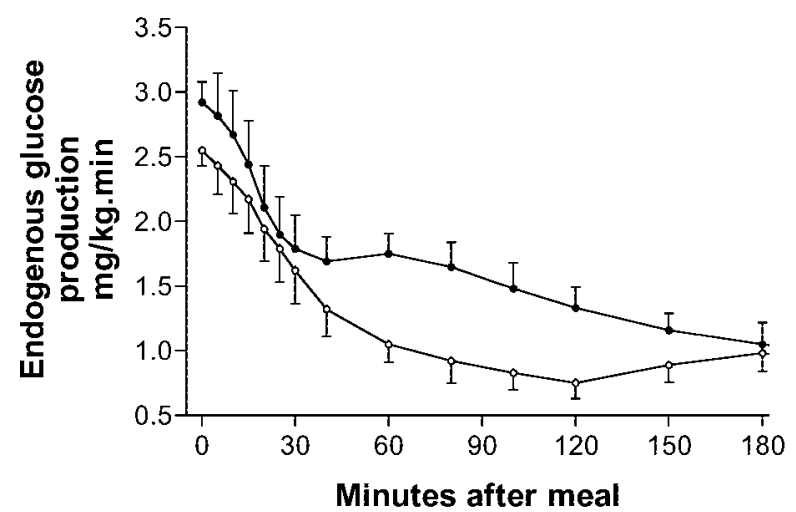

Fig. 4. Change in endogenous glucose production (EGP) during the early postmeal phase in the type 2 diabetic group $(\bullet)$ and the matched normal control group (O). Data are shown as means $\pm \mathrm{SE}$.

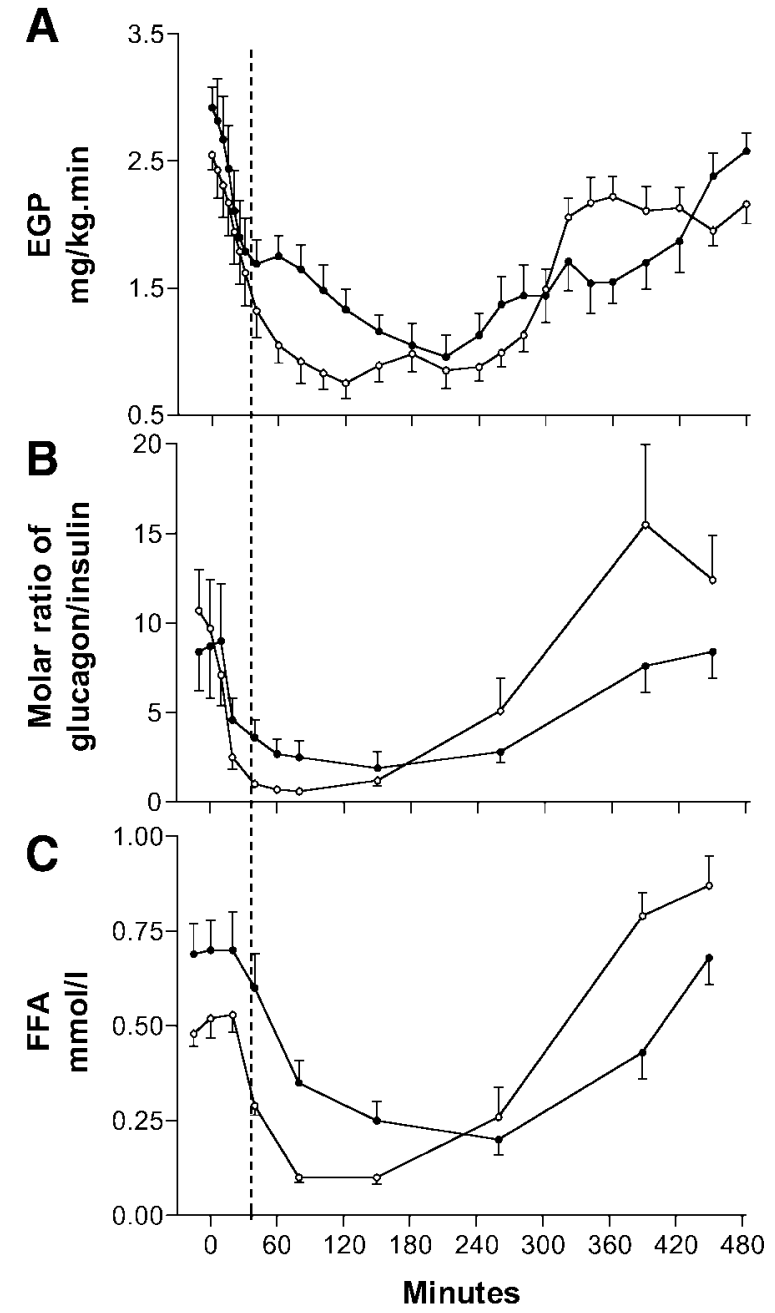

Fig. 5. A: time course of EGP during the entire study period after the test meal. $B$ : molar ratio of plasma glucagon to insulin. $C$ : change in plasma free fatty acid (FFA) concentration after the test meal in the type 2 diabetic group (•) and the matched normal control group ( $($ ). The vertical dashed line at $40 \mathrm{~min}$ is included to assist comparison between the relative time courses. Data are shown as means $\pm \mathrm{SE}$.

Plasma FFA. Fasting FFA concentration was higher in the diabetic group $(0.48 \pm 0.03$ vs. $0.69 \pm 0.08$ $\mathrm{mmol} / \mathrm{l}, P<0.05)$. Plasma FFA concentration fell to $0.09 \pm 0.05 \mathrm{mmol} / \mathrm{l}$ at $80 \mathrm{~min}$ in the control group (Fig. 5 ). After remaining suppressed for over $3 \mathrm{~h}$, plasma FFA concentration rebounded, reaching $0.87 \pm 0.06$ $\mathrm{mmol} / \mathrm{l}$ at $460 \mathrm{~min}$. In the diabetic group, FFA concentration had fallen by $80 \mathrm{~min}$, but it remained elevated compared with controls $(0.35 \pm 0.01 \mathrm{mmol} / \mathrm{l}, P<$ $0.005)$. The lowest concentration was not reached until $270 \mathrm{~min}(0.20 \pm 0.10 \mathrm{mmol} / \mathrm{l}, P<0.05$ compared with controls at $80 \mathrm{~min}$ ).

Glucose oxidation. Net glucose oxidation rate in the basal state was higher in the control than the diabetic group $\left(1.69 \pm 0.14\right.$ vs. $1.14 \pm 0.10 \mathrm{mg} \cdot \mathrm{kg}^{-1} \cdot \mathrm{min}^{-1}, P=$ 0.01 ). The rate of rise was similar in both groups such that, at peak net glucose oxidation rate in the control group (180 min), there was a significant difference between the groups $(2.35 \pm 0.22$ vs. $1.69 \pm 0.25 \mathrm{mg}$. $\mathrm{kg}^{-1} \cdot \min ^{-1}, P<0.05$; Fig. 7). In the diabetic group, 


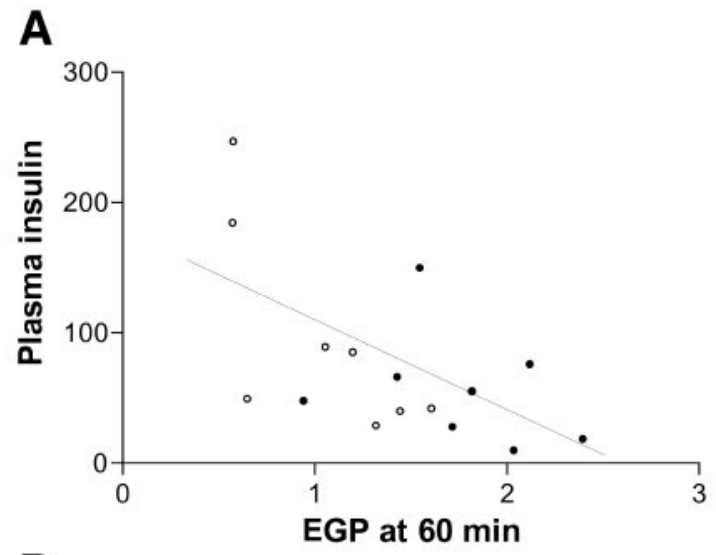

B

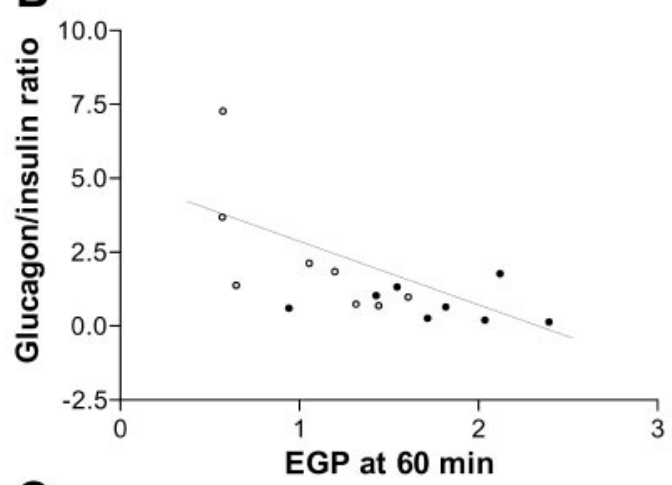

C

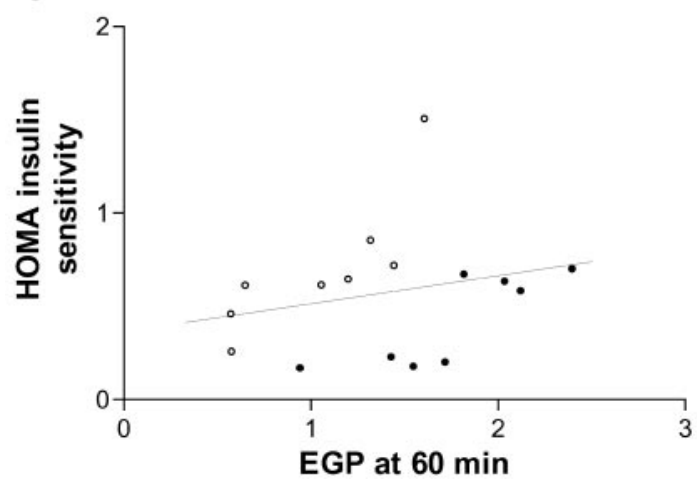

Fig. 6. Relationships between EGP $60 \mathrm{~min}$ after the meal and plasma insulin at $60 \mathrm{~min}(A)$, plasma glucagon/insulin ratio $(B)$, and homeostatic model assessment (HOMA) index of insulin sensitivity $(C)$.

peak rates were achieved at $240 \min (1.82 \pm 0.26$ $\left.\mathrm{mg} \cdot \mathrm{kg}^{-1} \cdot \mathrm{min}^{-1}\right)$. In both groups, carbohydrate oxidation rates declined thereafter.

Urinary glucose excretion. During the early postprandial period (0-210 min), urinary glucose excretion rate was $0.29 \pm 0.22 \mathrm{mg} \cdot \mathrm{kg}^{-1} \cdot \mathrm{min}^{-1}$, and between 210 and $480 \mathrm{~min}$ it was $1.9 \pm 0.9 \mathrm{mg} \cdot \mathrm{kg}^{-1} \cdot \mathrm{min}^{-1}$ in the diabetic group. There was no quantifiable loss of glucose in urine in the control group.

\section{DISCUSSION}

This study demonstrates the time course and extent of suppression of EGP after a mixed meal in subjects with type 2 diabetes. The initial rate of suppression was similar in the diabetic and matched control groups but was not sustained in the diabetic group, such that EGP was $47 \%$ higher between 60 and 240 min after eating. This is important, as meals are normally taken every $4-5 \mathrm{~h}$ during waking hours. The nadir of EGP was delayed by $120 \mathrm{~min}$, and, unlike in the control group, this was not sustained. In both groups, plasma insulin increased briskly during the initial $20 \mathrm{~min}$. Subsequently, plasma insulin in the type 2 diabetic group rose more slowly to a subnormal peak. Conversely, plasma glucagon concentrations were higher in the diabetic group throughout the postprandial period. One hour after the meal, the degree of suppression of EGP correlated with plasma insulin and with the insulin/glucagon ratio.

Hepatic insulin resistance is widely believed to play an important role in the pathophysiology of type 2 diabetes $(5,20,27)$. The observed modest elevation of fasting plasma insulin in the type 2 diabetic subjects, together with the slightly elevated EGP and the subnormal suppression of EGP between 60 and $240 \mathrm{~min}$, are consistent with this. However, the present data indicate that the response to a similar acute increment in hepatic sinusoidal insulin concentration produces the same initial rate of suppression of EGP in type 2 diabetic subjects and matched controls (Fig. 4). These observations were made under the normal day-to-day circumstances of elevated plasma glucose and glucagon in type 2 diabetes, and direct inferences about hepatic insulin sensitivity cannot be made. Glucose effectiveness in suppression of EGP is similar in normal and diabetic subjects (4); hence, the elevated plasma glucose will exert an additional suppressive effect in the diabetic group. However, the apparently normal acute hepatic insulin responsiveness under everyday conditions is of interest. In contrast to the universal observation of insulin resistance of muscle in type 2 diabetes, normal insulin sensitivity of the liver has previously been reported by use of exogenous insulin infusion to mimic postprandial profiles (36). The same group demonstrated a normal rate of onset of hepatic insulin action (68). In obese type 2 diabetic subjects, elevation of plasma insulin to a mean of $30 \mathrm{mU} / \mathrm{l}$ was observed to be associated with fall in EGP of 51 vs. 54

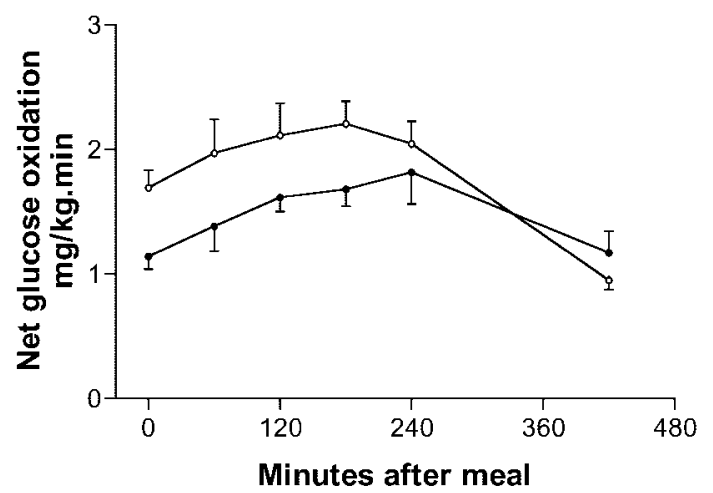

Fig. 7. Change in glucose oxidation rates after the meal in the type 2 diabetic group $(\bullet)$ and the matched normal control group (०). Data are shown as means $\pm \mathrm{SE}$. 
$\mathrm{mg} \cdot \mathrm{m}^{-2} \cdot \mathrm{min}^{-1}$ in control and diabetic groups, respectively (64). The present data confirm the everyday physiological relevance of acute insulin responsiveness of the liver in type 2 diabetes, although between 60 and 240 min after eating, higher ambient insulin levels do not achieve normal suppression of EGP. Because glucose transport is the major insulin-insensitive step in muscle in type 2 diabetes (57), and because glucose transport is not rate limiting for hepatic glucose metabolism, it would be expected that liver and muscle differ in expression of insulin resistance. It is noteworthy that postprandial EGP correlated with HOMA, an index based on the fasting state. The data on EGP reported in the present study includes a renal component, and the latter has been reported to rise after eating (45).

The control subjects demonstrated a prompt decrease in EGP, although this was less rapid than previously observed in young normal subjects (66), and possible reasons for this must be considered. The meals in the two studies were made up of identical proportions of carbohydrate, protein, and fat, although the total energy content was modestly less in the present study (550 vs. $650 \mathrm{kcal}$ ). It is unlikely that this had a major impact on initial rates of EGP suppression. Age per se is unlikely to be responsible, as neither peripheral nor hepatic insulin sensitivity changes with age, provided physical activity and obesity are matched (11). The considerable difference in body mass index (BMI; $30 \mathrm{vs.} 21 \mathrm{~kg} / \mathrm{m}^{2}$ ) between the previously studied subjects and the control subjects in the present study may explain the observations. Obesity itself could be exerting an effect by changing the availability of intrahepatic fatty acids in the hepatic sinusoids (7). In the present study, the two groups were well matched for BMI. The diabetic and control groups demonstrated an identical rate of suppression of EGP over the first 30 min after commencing the meal. However, suppression of EGP was much slower in the diabetic group thereafter. This pattern of abnormality raises the question of precisely which factors regulate EGP during the postprandial period. Both the major regulatory hormones $(31,40,42)$ and change in plasma FFA (6) have to be considered.

The rate of rise in plasma insulin concentration in the first $20 \mathrm{~min}\left(6.4 \mathrm{pmol} \cdot 1^{-1} \cdot \mathrm{min}^{-1}\right)$ in this group of diabetic subjects was striking and at 20 min represented $40.1 \%$ of the subsequent peak concentration compared with $43.3 \%$ in the control subjects. Although the initial insulin response to eating may appear unexpectedly great for subjects with type 2 diabetes, previous studies of such subjects after a mixed meal rather than pure glucose have reported a similar change in plasma insulin (59). The ability of intravenous arginine to elict normal early insulin-secretory responses in type 2 diabetes has been recognized for many years (51). The mixed meal administered in the present study would bring about a stimulus to the pancreas by the increment in plasma amino acids and glucose as happens in everyday life. The subjects were at a relatively early stage of the disease and were reasonably well controlled on diet alone. The actual change in hepatic sinusoidal insulin concentration will be underestimated by measurements on peripheral plasma samples. Portal vein insulin concentrations are $\sim 2.4$-fold greater than peripheral plasma concentrations during steady-state conditions (12), and during the initial phase of increasing insulin concentration the degree of increase over basal will be considerably greater. Hence, in the $20 \mathrm{~min}$ after eating, the liver would be exposed to an increase in insulin concentration from $\sim 160 \mathrm{pmol} / /$ (2.4 times peripheral levels) to well over $460 \mathrm{pmol} / \mathrm{l}$ in the diabetic group. This considerable change could be supramaximal with respect to inducing initial change in EGP, the increase to $>630$ $\mathrm{pmol} / \mathrm{l}$ in the controls achieving only a similar rate of suppression of EGP. The subsequent pattern of insulin secretion differs markedly between the groups (Fig. 1), and the sustained difference is consistent with the slower subsequent suppression of EGP in the diabetic group between 60 and $240 \mathrm{~min}$. This analysis of change in the concentrations of one hormone does not by itself explain the pattern of the EGP response to insulin, and the effect of simultaneous change in glucagon concentration must be considered.

Glucagon exerts a powerful effect on EGP (31). Plasma glucagon levels increased more markedly in the diabetic group (Fig. 1), and, during the important phase from 60 to 240 min after eating, plasma glucagon levels were elevated approximately twofold in the diabetic group compared with the controls. Similar data in type 2 diabetes have previously been reported $(2,62)$. This is generally consistent with an effect on the observed pattern of EGP but, as with the pattern of change of insulin, it does not match the time course of change in EGP in the two groups. However, if the hormones are regarded as part of a coordinated response to eating and the molar ratio of glucagon to insulin is calculated, a different picture emerges. It can be seen from Fig. 5 that the glucagon/insulin ratio changes in a manner highly suggestive of this being the major regulatory factor. A similar close relationship was previously observed in the study of young healthy subjects (66). Although the concept of dual regulation of EGP by glucagon and insulin is not new (69), it has not previously been linked so closely to physiological regulation in vivo.

Several previous studies have indicated a role for FFA in controlling EGP $(9,13,26,52,55,60)$. The "single gateway hypothesis" was originally put forward to integrate observations on change in plasma hormones and FFA, suggesting that peripheral action of hormones exerted effects on the liver primarily by modulating plasma FFA concentrations (6). However, some studies have not observed any effect of FFA on EGP $(53,58)$, and evidence exists to suggest that insulin acts directly to inhibit EGP (42). In the present study, FFA concentration did not change in control and diabetic groups, respectively, in the $20 \mathrm{~min}$ after eating, whereas EGP fell by 25 and 35\%, respectively, over the same time. In the 40 min after eating, FFA concentration fell by 42 and $14 \%$ in control and diabetic 
groups, and EGP fell by 59 and 57\%, respectively, over the same time. The relatively slow and small change in plasma FFA has to be compared with the major rapid changes in plasma insulin and glucagon. The comparative time courses are shown in Fig. 6. There were, however, weak correlations between basal FFA and the extent of suppression of EGP $(r=0.54, P<0.05)$ and between the decrease of FFA concentrations at $40 \mathrm{~min}$ and the time to maximum suppression of EGP $(r=$ $-0.58, P<0.05)$. The observations do not support the concept of an important acute role for plasma FFA in regulating EGP but do not exclude the possibility of regulation over longer periods. It has recently been demonstrated that $8 \mathrm{~h}$ of lipid infusion blunted suppression of EGP during a hyperinsulinemic clamp (61).

Non-steady-state errors in the estimation of EGP can be avoided if the tracer specific activity of endogenous glucose is maintained constant during meal absorption. If a continuous infusion of tracer is used throughout the postprandial period, the specific activity will rise sharply as EGP is suppressed. By steady-state theory, this will cause EGP to be overestimated after a meal and, hence, create the appearance of slow suppression $(15,25,34,49)$. Indeed, previous studies using a constant tracer infusion after an oral glucose load have reported slow suppression in both normal and diabetic subjects to $20-50 \%$ of basal $\operatorname{EGP}(24,33,46)$. A similar problem of overestimation has been identified if tracer specific activity is increasing during estimation of fasting EGP (48). In the present study, this difficulty was avoided in the basal state by adequate priming of the glucose pool and in the postprandial state by adjusting the rate of tracer infusion in a stepwise manner to match the expected decrease in EGP. Our previous work (66) in young healthy subjects demonstrated that constant specific activity of endogenous glucose could be achieved using this technique. Previous work on human subjects has demonstrated normal rates of glucose absorption in type 2 diabetes (3).

Knowledge of the dynamics of change in EGP after eating, coupled with observations on whole body glucose oxidation rates, allows an analysis of the factors underlying postprandial hyperglycemia in type 2 diabetes. During the 30 min after eating, the suppression of EGP did not account for any major difference between control and diabetic groups. However, by $60 \mathrm{~min}$ after eating, plasma glucose had reached maximum in the controls, but in the diabetic group it was still rising at $2.1 \mathrm{mg} \cdot \mathrm{kg}^{-1} \cdot \mathrm{min}^{-1}$ (Fig. 1). At $60 \mathrm{~min}$, the difference in EGP between the groups was 0.70 $\mathrm{mg} \cdot \mathrm{kg}^{-1} \cdot \mathrm{min}^{-1}$ (Fig. 4), this representing $33 \%$ of the excess accumulation of glucose in extracellular fluid. The difference in glucose oxidation rates was 0.63 $\mathrm{mg} \cdot \mathrm{kg}^{-1} \cdot \mathrm{min}^{-1}$, or $30 \%$ of the excess accumulation of glucose. The remainder must be accounted for by inadequate rates of glucose disposal. It can thus be seen that inadequate suppression of EGP, subnormal glucose oxidation rate, and slow tissue uptake of glucose are each an important factor in the genesis of postprandial hyperglycemia in type 2 diabetes. Previous studies using magnetic resonance spectroscopy have demonstrated that, at $5 \mathrm{~h}$ after eating in nondiabetic subjects, $\sim 20 \%$ of the absorbed carbohydrate is stored in liver and $30 \%$ in muscle $(65,67)$. This is very different from the pattern during hyperinsulinemic clamp studies. Previous evidence suggests that the relative disposition of glucose in muscle and liver differs considerably after oral and intravenous routes $(1,32,47)$. In conclusion, direct study of the pathophysiological changes after eating has allowed quantitation of the major factors underlying postprandial hyperglycemia in type 2 diabetes.

We are grateful to Jean Gerrard for help with the clinical studies, Marie Caraher for expert dietary assistance, Dr. Stuart Bennett for clinical expertise, and the volunteers for their time and cooperation.

This work was funded by Novo Nordisk and The Wellcome Trust (project grant no. 056418).

\section{REFERENCES}

1. Adkins BA, Myers SR, Hendrick GK, Stevenson RW, and Williams PE. Importance of the route of intravenous glucose delivery on hepatic glucose balance in the conscious dog. $J$ Clin Invest 79: 557-565, 1987.

2. Baron AD, Schaeffer L, Shragg P, and Kolterman OG. Role of hyperglucagonemia in maintenance of increased rates of hepatic glucose output in type II diabetics. Diabetes 36: 274-283, 1987.

3. Basu A, Basu R, Shah P, Vella A, Johnson CM, Jensen M, Nair KS, Schwenk WF, and Rizza RA. Type 2 diabetes impairs splanchnic uptake of glucose but does not alter intestinal glucose absorption during enteral glucose feeding: additional evidence for a defect in hepatic glucokinase activity. Diabetes 50 : 1351-1362, 2001.

4. Basu A, Caumo C, Bettini F, Gelisio A, Alzaid A, Cobelli C, and Rizza A. Impaired basal glucose effectiveness in NIDDM: contribution of defects in glucose disappearance and production, measured using an optimized minimal model independent protocol. Diabetes 46: 421-432, 1997.

5. Beck-Nielsen H, Hother-Nielsen O, Vaag A, and Alford F. Pathogenesis of type 2 (non-insulin-dependent) diabetes mellitus: the role of skeletal muscle glucose uptake and hepatic glucose production in the development of hyperglycaemia. A critical comment. Diabetologia 37: 217-221, 1994.

6. Bergman R. New concepts in extracellular insulin signalling: the single gateway hypothesis. Recent Prog Horm Res 97: 359385, 1997.

7. Bergman RN. Non-esterified fatty acids and the liver: why is insulin secreted into the portal vein? Diabetologia 43: 946-952, 2000.

8. Bier DM, Leake RD, Haymond MW, Arnold KJ, Gruenke LD, Sperling MA, and Kipnis DM. Measurement of true glucose production rates in infants and childhood with 6,6dideuterated glucose. Diabetes 26: 1016-1023, 1977.

9. Boden G, Chen X, Ruiz J, White JV, and Rossetti L. Mechanism of fatty acid induced inhibition of glucose uptake. J Clin Invest 93: 2438-2446, 1994.

10. Bogardus C, Lillioja S, Stone K, and Mott D. Correlation between muscle glycogen synthase activity and in vivo insulin action in man. J Clin Invest 73: 1185-1190, 1984.

11. Broughton DL, Webster J, and Taylor R. Insulin sensitivity and secretion in healthy elderly human-subjects with "abnormal" glucose tolerance. Eur J Clin Invest 22: 582-590, 1992.

12. Cherrington AD, Edgerton D, and Sindelar DK. The direct and indirect effects of insulin on hepatic glucose production in vivo. Diabetologia 41: 987-996, 1998.

13. Clore JN, Glickman PS, Nestler JE, and Blackard WG. In vivo evidence for hepatic autoregulation during FFA-stimulated gluconeogenesis in normal humans. Am J Physiol Endocrinol Metab 261: E425-E429, 1991. 
14. Cobelli C, Foster D, and Toffolo G. Tracer Kinetics in Biomedical Research: From Data to Model. New York: Kluwer Academic/Plenum, 2000.

15. Cobelli C, Mari A, and Ferrannini E. Nonsteady state: error analysis of Steele's model and developments for glucose kinetics. Am J Physiol Endocrinol Metab 252: E679-E689, 1987.

16. Cobelli $\mathbf{C}$ and Toffolo G. Constant specific activity input allows reconstruction of endogenous glucose concentration in nonsteady state. Am J Physiol Endocrinol Metab 258: E1037E1040, 1990.

17. Cooper BG, McClean JA, and Taylor R. Evaluation of the Deltatrac indirect calorimeter by gravimetric gas injection and alcohol burning. Clin Phys Physiol Meas 12: 333-341, 1991.

18. DECODE Study Group. Glucose tolerance and mortality: comparison of WHO and American Diabetes Association diagnostic criteria. Lancet 354: 617-621, 1999.

19. DeFronzo RA. The triumvirate: beta-cell, muscle, liver: a collusion responsible for NIDDM. Diabetes 37: 667-687, 1988.

20. DeFronzo RA, Bonadonna RC, and Ferrannini E. Pathogenesis of NIDDM: a balanced overview. Diabetes Care 15: 318 368, 1992.

21. DeFronzo RA, Simonson D, and Ferrannini E. Hepatic and peripheral insulin resistance: a common feature of type 2 (noninsulin dependent) and type 1 (insulin dependent) diabetes mellitus. Diabetologia 23: 313-319, 1982.

22. Diamanti-Kandarakis E, Kouli C, Tsianateli T, and Bergiele A. Therapeutic effects of metformin on insulin resistance and hyperandrogenism in polycystic ovary syndrome. Eur $J$ Endocrinol 138: 269-274, 1998.

23. Elia M, Folmer P, Schlatmann A, Goren A, and Austin S. Carbohydrate, fat and protein metabolism in muscle and in the whole body after mixed meal ingestion. Metabolism 37: 542-551, 1988.

24. Ferrannini E, Bjorkman O, Reichard GA, Pilo A, Olsson M, and Wahren $\mathbf{J}$. The disposal of an oral glucose load in healthy subjects: a quantitative study. Diabetes 34: 580-588, 1985.

25. Finegood DT, Bergman RN, and Vranic M. Estimation of endogenous glucose production during hyperinsulinemic-euglycemic glucose clamps: comparison of unlabelled and labelled exogenous glucose infusates. Diabetes 36: 914-924, 1987.

26. Fulcher GR, Walker M, Catalano C, Agius L, and Alberti KGMM. Metabolic effects of suppressions of non-esterified fatty acid levels with acipimox in obese NIDDM subjects. Diabetes 41: 1400-1408, 1992.

27. Gerich JE. Is muscle the major site of insulin resistance in type 2 (non-insulin-dependent) diabetes mellitus? Diabetologia 34: 607-610, 1991.

28. Hanefeld M, Fischer S, Julius U, Schulze J, Schwanebeck U, Schmechel H, Ziegelasch HJ, and Lindner J. Risk factors for myocardial infarction and death in newly detected NIDDM: the Diabetes Intervention Study, 11-year follow-up. Diabetologia 39: 1577-1583, 1996.

29. Harrison J, Hodson AW, Skillen AW, Stappenbeck R, Agius L, and Alberti KGMM. Blood glucose, lactate, pyruvate, glycerol, 3-hydroxybutyrate, and acetoacetate measurements in man using a centrifugal analyser with a fluorimetric attachment. J Clin Chem Clin Biochem 26: 141-146, 1988.

30. Hollenbeck CB, Chen Y-DI, and Reaven GM. A comparison of the relative effects of obesity and non-insulin dependent diabetes mellitus on in vivo insulin stimulated glucose utilization. Diabetes 33: 622-626, 1984.

31. Holste LC, Connolly CC, Moore MC, Neal DW, and Cherrington AD. Physiological changes in circulating glucagon alter hepatic glucose disposition during portal glucose delivery. Am $J$ Physiol Endocrinol Metab 273: E488-E496, 1997.

32. Ishida T, Chou J, Lewis R, Hartley R, Entman M, and Field JB. Differential effects of oral, peripheral intravenous, and intraportal glucose on hepatic glucose uptake and insulin and glucagon extraction in conscious dogs. $J$ Clin Invest 72 : 590-600, 1983.

33. Jackson RA, Roshania RD, Hawa MI, Sim BM, and DiSivio L. Impact of glucose ingestion on hepatic and peripheral glucose metabolism in man: an analysis based on simultaneous use of the forearm and double isotope techniques. $J$ Clin Endocrinol Metab 63: 541-549, 1986.

34. Jacquez JA. Theory of production rate calculations in steady and nonsteady states and its application to glucose metabolism. Am J Physiol Endocrinol Metab 262: E779-E790, 1992.

35. Jones IR, Owens DR, Luzio S, Williams S, and Hayes TM. The gastrointestinal inhibitory peptide response to oral glucose and mixed meals is increased in patients with type 2 (NIDDM) diabetes mellitus. Diabetologia 32: 668-677, 1989.

36. Katz H, Homan M, Jensen M, Caumo A, Cobelli C, and Rizza R. Assessment of insulin action in NIDDM in the presence of dynamic changes in insulin and glucose concentration. Diabetes 43: 289-296, 1994.

37. Katz LD, Glickman MG, Rapoport S, Ferrannini E, and DeFronzo RA. Splanchnic and peripheral disposal of oral glucose in man. Diabetes 32: 675-679, 1983.

38. Kelley D, Mitrakou A, Schwenk F, Benn J, Sonnenberg G, Arcangell M, Aoki T, Sorensen J, Berger M, Sonksen P, and Gerich J. Skeletal muscle glycolysis, oxidation, and storage of an oral glucose load. J Clin Invest 81: 1563-1571, 1988.

39. Knox DP and Jones DG. Automated enzymic determination of free fatty acids by centrifugal analysis. J Auto Chem 6: 152-154, 1984.

40. Lewis GF, Vranic M, and Giacca A. Glucagon enhances the direct suppressive effect of insulin on hepatic glucose production in humans. Am J Physiol Endocrinol Metab 272: E371-E378, 1997.

41. Lusk G. Analysis of the oxidation of mixtures of carbohydrate and fat. J Biol Chem 59: 41-42, 1924.

42. Maheux P, Chen YD, Polonsky KS, and Reaven GM. Evidence that insulin can directly inhibit hepatic glucose production. Diabetologia 40: 1300-1306, 1997.

43. Matthews DR, Hosker JP, Rudenski AS, Naylor BA, Treacher DF, and Turner R. Homeostasis model assessment: insulin resistance and B-cell function from fasting plasma glucose and insulin. Diabetologia 28: 412-419, 1985.

44. McMahon M, Marsh H, and Rizza RA. Comparison of the pattern of postprandial carbohydrate metabolism after ingestion of a glucose drink or a mixed meal. J Clin Endocrinol Metab 68: 647-653, 1989.

45. Meyer C, Dostou JM, Welle WL, and Gerich JE. Role of human liver, kidney, and skeletal muscle in postprandial glucose homeostasis. Am J Physiol Endocrinol Metab 282: E419-E427, 2002.

46. Mitrakou A, Kelley D, Veneman T, Jenssen T, Pangburn T, Reilly J, and Gerich J. Contribution of abnormal muscle and liver glucose metabolism to postprandial hyperglycemia in NIDDM. Diabetes 39: 1381-1390, 1990.

47. Myers SR, Biggers DW, Neal DW, and Cherrington AD. Intraportal glucose delivery enhances the effects of hepatic glucose load on net glucose uptake in vivo. J Clin Invest 88: 158$167,1991$.

48. Hother-Nielsen $\mathbf{O}$ and Beck-Nielsen, H. On the determination of basal glucose production rate in patients with type 2 (non-insulin dependent) diabetes mellitus using primed-continuous 3-3H-glucose infusion. Diabetologia 33: 603-610, 1990.

49. Norwich KN. Molecular dynamics. In: The Kinetics of Tracers in the Intact Organism. Oxford, UK: Pergammon, 1977.

50. Orskov H, Thomsen HG, and Yde H. Wick chromatography for rapid and reliable immunoassay of insulin, glucagon and growth hormone. Nature 219: 193-195, 1968.

51. Pfeifer MA, Halter JB, and Porte D. Insulin secretion in diabetes mellitus. Am J Med 70: 579-588, 1981.

52. Prager R, Wallace $\mathbf{P}$, and Olefsky JM. Direct and indirect effects of insulin to inhibit hepatic glucose output in obese subjects. Diabetes 36: 607-611, 1987.

53. Puhakainen I and Yki-Järvinen H. Inhibition of lipolysis decreases lipid oxidation and gluconeogenesis from lactate but not fasting hyperglycemia or total hepatic glucose procduction in NIDDM. Diabetes 42: 1694-1699, 1993.

54. Radziuk J, Norwich KH, and Vranic M. Experimental validation of measurements of glucose turnover in nonsteady state. Am J Physiol Endocrinol Metab Gastrointest Physiol 234: E84E93, 1978. 
55. Rebrin K, Steil GM, Getty L, and Bergman R. Free fatty acid as a link in the regulation of hepatic glucose output by peripheral insulin. Diabetes 44: 1038-1045, 1995.

56. Rizza RA, Mandarino LJ, and Gerich JE. Dose-response characteristics for effects of insulin on production and utilization of glucose in man. Am J Physiol Endocrinol Metab 240: E630E639, 1981.

57. Roden M, Price TB, Perseghin G, Petersen KF, Rothman DL, Cline GW, and Shulman GI. Mechanism of free fatty acid-induced insulin resistance in humans. J Clin Invest 97: 2859-2865, 1996.

58. Saloranta C, Taskinen MR, Widen E, Harkonen M, Melander A, and Groop L. Metabolic consequences of sustained suppression of free fatty acids by acipimox in patients with NIDDM. Diabetes 42: 1559-1566, 1993.

59. Samad AHB, Ty Willing TS, Alberti KGMM, and Taylor R. Effects of BAYm 1099, new alpha-glucosidase inhibitor, on acute metabolic responses and metabolic control over 1 month. Diabetes Care 11: 337-344, 1988.

60. Schimek RA and Lieberman WJ. The influence of cyclogyl and neosynephrine on tonographic studies of muitic control in open angle glaucoma. Br J Ophthalmol 51: 781-784, 1961.

61. Shah P, Vella A, Basu A, Basu R, Adkins A, Schwenk WF, Johnson CM, Nair KS, Jensen MD, and Rizza RA. Effects of free fatty acids and glycerol on splanchnic glucose metabolism and insulin extraction in nondiabetic humans. Diabetes 51: 301$310,2002$.

62. Shah P, Vella A, Basu A, Basu R, Schwenk WF, and Rizza RA. Lack of suppression of glucagon contributes to postprandial hyperglycemia in subjects with type 2 diabetes. J Clin Endocrinol Metab 85: 4053-4059, 2000.

63. Sparcino G, Pillonetto G, Capello M, DeNicolao G, and Cobelli C. WINSTODEC: a stochastic deconvolution interactive program for physiological and pharmacokinetic systems. Comput Methods Programs Biomed 67: 67-77, 2002.

64. Staehr P, Hother-Nielsen O, Holst JJ, and Beck-Nielsen H. Assessment of hepatic insulin action in obese type 2 diabetic patients. Diabetes 50: 1363-1370, 2001.

65. Taylor R, Magnussen I, Rothman DL, Cline GW, Caumo A, Cobelli C, and Shulman GI. Direct assessment of liver glycogen storage by $13 \mathrm{C}$-nuclear magnetic resonance spectroscopy and regulation of glucose homeostasis after a mixed meal in normal subjects. J Clin Invest 97: 126-132, 1996.

66. Taylor R, Magnusson I, Rothman DL, Cline GW, Caumo A, Cobelli C, and Shulman GI. Direct assessment of liver glycogen storage by $13 \mathrm{C}$ nuclear magnetic resonance spectroscopy and regulation of glucose homeostasis after a mixed meal in normal subjects. J Clin Invest 97: 126-132, 1996.

67. Taylor R, Price TB, Katz LD, Shulman RG, and Shulman GI. Direct measurement of change in muscle glycogen concentration after a mixed meal in normal subjects. Am J Physiol Endocrinol Metab 265: E224-E229, 1993.

68. Turk D, Alzaid A, Dinneen S, Nair KS, and Rizza R. The effects of non insulin dependent diabetes mellitus on the kinetics of onset of insulin action in hepatic and extrahepatic tissues. $J$ Clin Invest 95: 755-762, 1995.

69. Unger RH. Glucagon physiology and pathophysiology in the light of new advances. Diabetologia 28: 574-578, 1985.

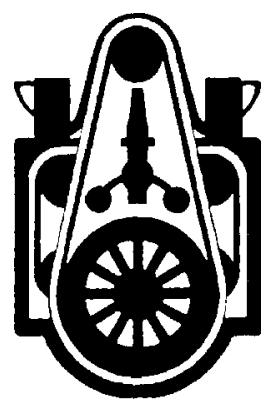

